\title{
Salivary gland derived peptides as a new class of anti-inflammatory agents: review of preclinical pharmacology of C-terminal peptides of SMR1 protein
}

\author{
Ronald D Mathison ${ }^{1 *}$, Joseph S Davison ${ }^{1}$, A Dean Befus², Daniel A Gingerich ${ }^{3}$
}

\begin{abstract}
The limitations of steroidal and non steroidal anti-inflammatory drugs have prompted investigation into other biologically based therapeutics, and identification of immune selective anti-inflammatory agents of salivary origin. The traditional view of salivary glands as accessory digestive structures is changing as their importance as sources of systemically active immunoregulatory and anti-inflammatory factors is recognized. Salivary gland involvement in maintenance of whole body homeostasis is regulated by the nervous system and thus constitutes a "neuroendocrine axis". The potent anti-inflammatory activities, both in vivo and in vitro, of the tripeptide Phe-Glu-Gly (FEG) are reviewed. FEG is a carboxyl terminal peptide of the prohormone SMR1 identified in the rat submandibular salivary gland, The D-isomeric form (feG) mimics the activity of its L-isomer FEG. Macropharmacologically, feG attenuates the cardiovascular and inflammatory effects of endotoxemia and anaphylaxis, by inhibition of hypotension, leukocyte migration, vascular leak, and disruption of pulmonary function and intestinal motility. Mechanistically, feG affects activated inflammatory cells, especially neutrophils, by regulating integrins and inhibiting intracellular production of reactive oxygen species. Pharmacodynamically, feG is active at low doses $(100 \mu \mathrm{g} / \mathrm{kg})$ and has a long (9-12 hour) biological half life. As a therapeutic agent, feG shows promise in diseases characterized by over exuberant inflammatory responses such as systemic inflammatory response syndrome and other acute inflammatory diseases. Arthritis, sepsis, acute pancreatitis, asthma, acute respiratory inflammation, inflammatory bowel disease, and equine laminitis are potential targets for this promising therapeutic peptide. The term "Immune Selective Anti-Inflammatory Derivatives" (ImSAIDs) is proposed for salivary-derived peptides to distinguish this class of agents from corticosteroids and nonsteroidal anti-inflammatory drugs.
\end{abstract}

\section{Introduction}

Saliva, best known for its digestive and protective properties in the maintenance of the health and integrity of the oral and gastric mucosa [1], is becoming increasingly recognized for its important role in regulating whole body homeostasis [2]. Although over the past half century many bioactive proteins and peptides have been identified in saliva $[3,4]$, salivary glands are still viewed primarily as accessory digestive structures that provide lubrication and digestive enzymes. However, it is now

\footnotetext{
* Correspondence: rmathiso@ucalgary.ca

'Faculty of Medicine, University of Calgary, 3330 Hospital Drive NW, Calgary, Alberta, T2N 4N1, Canada

Full list of author information is available at the end of the article
}

becoming clear that salivary endocrine factors play an important role in the modulation of systemic immune and inflammatory reactions. Classically, the salivary glands are generally considered as exocrine glands that dispense their protein and fluid externally into a lumen or a duct. However, investigations dating from 60 years ago suggested an unorthodox view that salivary and other exocrine glands, such as the pancreas, are capable of endocrine secretion, dispensing their secretions internally, i.e. directly into the blood stream. It has been suggested that these glands be called "duacrine" glands [5].

Salivary glands produce various immunoregulatory $[6,7]$ and anti-inflammatory [8] agents. The importance of the salivary gland in maintaining homeostasis has 
been clarified in recent decades by demonstration of neuroendocrine interactions between the nervous, endocrine, and immune systems [9]. The salivary glands, as well as the thymus and cervical lymph nodes, are innervated by noradrenergic fibers from the sympathetic trunk $[10,11]$, which were shown to modulate lymphocyte function within lymph nodes and thymus $[12,13]$.

This paper reviews the published pharmacologic and immunopharmacologic evidence that salivary gland derived peptides, with particular emphasis on the D-isomeric tripeptide feG, deserve consideration as potentially therapeutically useful anti-inflammatory agents.

\section{The Neuroendocrine Axis}

The existence of salivary-derived, systemically acting, anti-inflammatory factors and the regulation of salivary gland function by the sympathetic nervous system were demonstrated in anaphylaxis and endotoxemia models in rats. Superior cervical ganglionectomy significantly reduced mortality and greatly attenuated the influx of histamine, neutrophils, and serum-derived proteins, into bronchoalveolar fluid in anaphylaxis-induced pulmonary inflammation in rats [14]. However, the protective effect of superior cervical ganglionectomy was completely abolished in rats with concurrent bilateral sialadenectomy of the submandibular salivary glands [15]. These findings reveal that submandibular salivary glands produce systemically important immunomodulatory factors and that the cervical sympathetic nerves tonically inhibit the release of some of these factors. In an endotoxin-induced acute hypotension model, either bilateral superior cervical ganglionectomy or submandibular sialadenectomy resulted in significantly larger drops in blood pressure compared to intact controls [16] (Figure 1). These results indicate that the submandibular gland elaborates factors that protect against acute hypotension induced by endotoxin and that these factors are under the control of the cervical sympathetic nervous system.

\section{Bioactivity of Salivary Gland Extracts: SGP-T}

On the basis of the findings that salivary glands participate in modulating systemic inflammatory responses, bioactive factors were sought in saliva. Extracts of submandibular glands were subjected to molecular weight cut-off filtration and tested for bioactivity. A novel seven amino acid peptide with sequence Thr-Asp-IlePhe-Glu-Gly (TDIFEGG) was isolated, named submandibular peptide-T (SGP-T), and shown to express anti-allergic and anti-endotoxin activities[16,17]. SGP-T was identified as the carboxyl terminal of SMR1, a 146amino acid, multipotent prohormone product of the VCSa1 (variable coding sequence A1) gene [18], which is also identified as RATSMR1A, Smr1, SMR1 protein and VCS-alpha 1. Recent studies have shown that SMR1

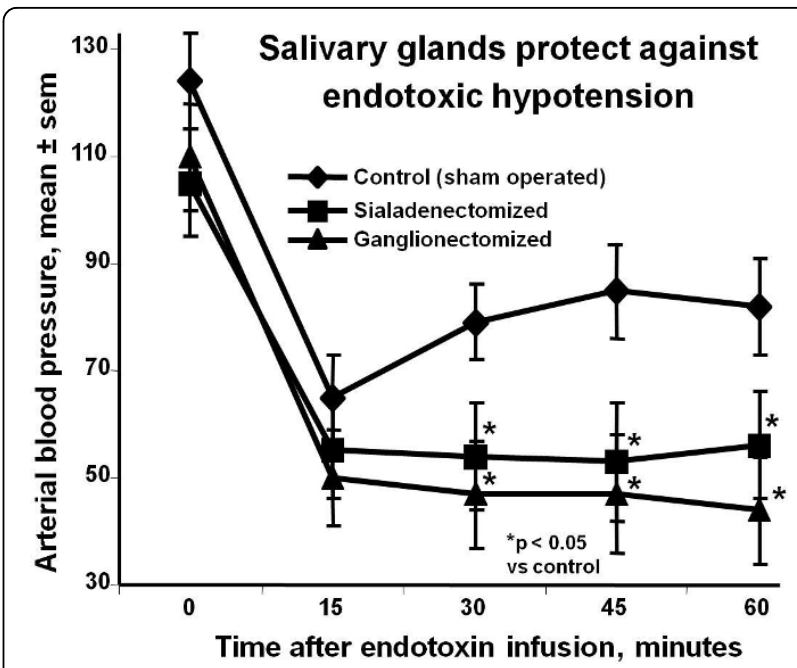

Figure 1 Neuroendocrine axis and modulation of responses to lipopolysaccharide: Intravenous administration of lipopolysaccharide (LPS) induces rapid reduction in blood pressure in rats. Either bilateral removal of the submandibular salivary glands (sialadenectomized) or the superior cervical ganglia (ganglionectomized) exacerbate the LPS-induced hypotension. (mean \pm sem, $n=6$ to 8). Adapted from [16].

is secreted into saliva in response to intraperitoneal administration of $\beta$-adrenergic and cholinergic agonists, and removal of the cervical sympathetic ganglia that innervate the salivary glands resulted in increased levels of SMR1 protein in the submandibular glands [19]. These observations are in keeping with a cervical sympathetic trunk - submandibular gland axis propounded previously [15].

In ovalbumin (OA) sensitized rats SGP-T at dosages of 35 and $100 \mu \mathrm{g} / \mathrm{kg}$ injected 10 minutes prior to OA challenge protected against anaphylactic hypotension [20]. Interestingly, neither lower nor higher doses (10 or $350 \mu \mathrm{g} / \mathrm{kg}$ ) of SGP-T were protective. In OA sensitized rats challenged intra-intestinally with OA, pretreatment with SGP-T dose-dependently reduced the incidence and duration of disrupted intestinal motility and prevented the development of diarrhea [20]. SGP-T treatment also significantly suppressed endotoxin-induced fever in rats [21]. Neutrophil migration into carrageenan soaked sponges was inhibited by SGP-T injected intravenously at $100 \mu \mathrm{g} / \mathrm{kg}$ at $-1,0$, or 4 hours after implantation [22]. Interestingly, dose-response assays showed a bell-shaped dose response curve; neither lower $(10 \mu \mathrm{g} / \mathrm{kg})$ or higher $(350 \mu \mathrm{g} / \mathrm{kg})$ inhibited neutrophil migration (Figure 2). SGP-T treatment also promoted a bell-shaped dose-dependent recovery in the ability of neutrophils obtained from carrageenan-soaked sponges to generate superoxide anion. In another study endotoxin-induced leukocyte rolling and adhesion, quantified in vivo by intravital microscopy of mesenteric venules in 


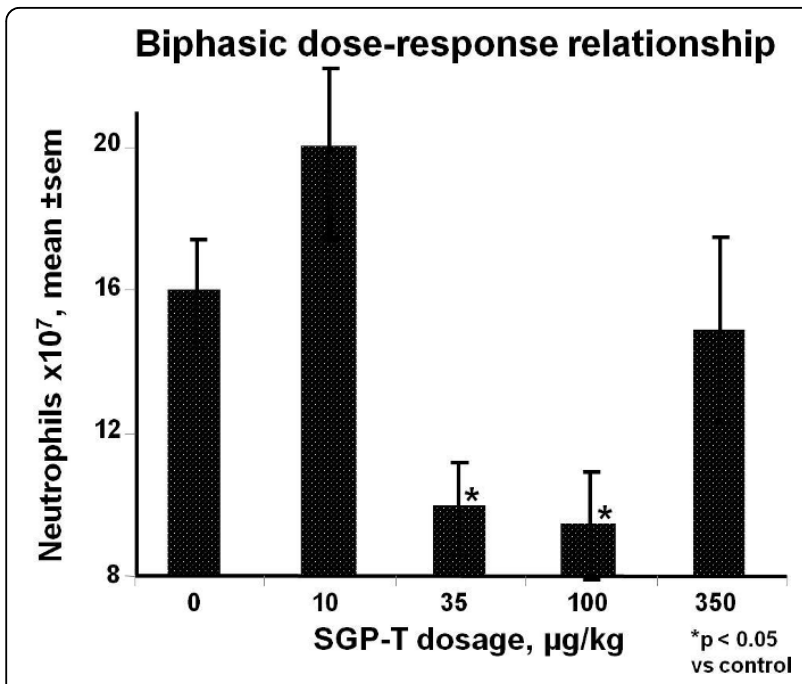

Figure 2 SGP-T and neutrophil chemotaxis: Neutrophil chemotaxis into carrageenan-soaked sponges over a 24 hour period in rats is inhibited by SGP-T injected intravenously, in a bell-shaped dose-dependent manner, at dosages indicated. (mean \pm sem, $n=3$ to 12). Adapted from [22].

anesthetized rats, was prevented by pre-treatment with SGP-T [23].

Before considering the pharmacology of SGP-T and its analogues a brief summary of the VCSa1 gene family and its products is presented as this subject was recently reviewed [24].

\section{The VCSa1 Gene Family}

The Vcsa1 gene that encodes the rat SMR1 protein is a member of the variable coding sequence multigene family, which share a common gene structure but exhibit extensive sequence variation in the coding region of the genes [25]. The VCS genes, which are divided into two subgroups VCSA and VCSB, are found exclusively in mammals [26]. The VCSA family, containing the Vcsa1 gene, has emerged recently, and exclusively in rodents, whereas the proline-rich VCSB family is found in all placental mammals [27]. Human members of the VCSB family include PROL1, SMR3B (PROL3), and SMR3A (PROL5) [24], and encode salivary and lacrimal secreted proline-rich proteins [28-30]. The SMR1 protein product of the rat $V c s a 1$ gene is cleaved into at least two biologically active peptides, sialorphin (QHNPR) and SGP-T (TDIFEGG) (Figure 3). Whereas the N-terminal QHNPR sequence is conserved in all products of the rat VCSA family members, the C-terminal TDIFEGG sequence is absent due to mutation or truncation of the C-terminus [27]. With the absence of the VCSA subgroup of genes in non-rodent mammals, sialorphin and SGP-T may not be present, although homologues of these peptides are encoded by VCSB

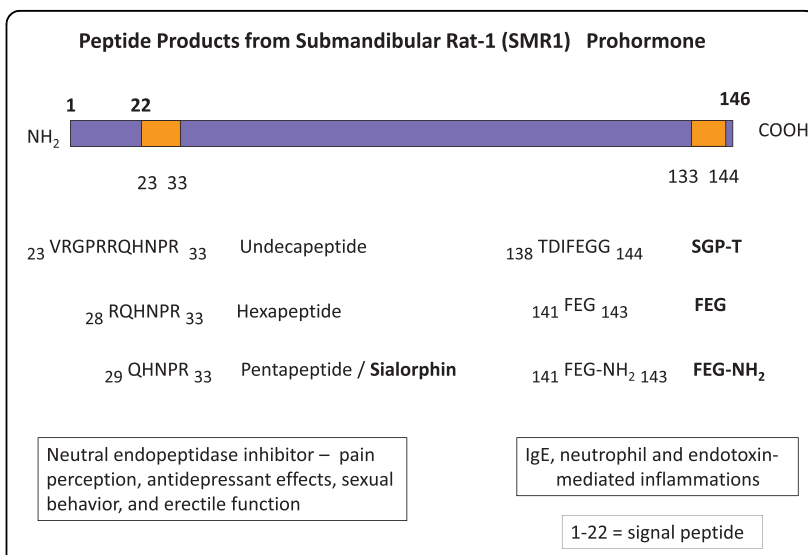

Figure 3 eptide Products from Submandibular Rat-1 (SMR1) Prohormone: The SMR1 precursor protein contains sialorphin near the N-terminal, and SGP-T (submandibular gland peptide T) near the C-terminal. FEG and FEG $\left(\mathrm{NH}_{2}\right)$ are biologically active derivatives of SGP-T.

genes. The human VCSB gene PROL1 encodes a protein that contains a QRFSR motif (opiorphin) that is functionally equivalent to rat sialorphin [31], although a homologue of TDIFEGG (SGP-T) has not been identified yet. Sialorphin participates in diverse physiological processes, such as pain perception, antidepressant effects, sexual behavior, and erectile function [4,32-34], and these actions appear to be related the inhibition of neutral endopeptidase (NEP)[4]. Human opiorphin has similar activity [35]. Vcsa1 expression is hormonally regulated by androgens [33,36], and the expression of opiorphin family genes may be similarly regulated [37].

\section{Pharmacology of the Tripeptide D-PHE-D-GLU- GLY (feG)}

During SGP-T isolation and testing procedures, the truncated sequence Phe-Glu-Gly (FEG) was identified, which itself showed bioactivity, as did its D-isomeric form (feG) [17]. This tripeptide sequence was synthesized and characterized pharmacologically in various models.

\section{Animal Models}

Several rat models of systemic inflammatory disease, and in vitro or ex vivo immunopharmacologic assays were utilized to test the bioactivity of feG as follows.

- Endotoxemia models. Injection of lipopolysaccharide (LPS) in rats results in rapid transient decreases in blood pressure, increases in circulating leukocytes, migration of leukocytes into peritoneal fluid, accumulation of neutrophils in cardiac tissue, disrupted intrinsic rhythmicity of migrating myoelectric complexes (MMC) in intestines, etc.

- Anaphylaxis. Rats sensitized to ovalbumin (OA) or larvae of Nippostrongylis braziliensis (Nb) and 
subsequently challenged with these same antigens by injection, orally, or intra-nasally depending on the purposes of the experiment, develop rapid drops in blood pressure; accumulation of leukocytes in cardiac tissue; increases in vascular permeability; increased circulating leukocytes; diarrhea and disrupted MMCs; and IgEmediated migration of eosinophils, neutrophils, and monocytes into airways.

- Pulmonary bronchoconstriction (measured by specific lung resistance) and airway hyper-responsiveness to methacholine or carbachol in sheep naturally allergic to Ascaris suum or in rats sensitized with either OA or with larvae of $\mathrm{Nb}$ and challenged by aerosol administration of the sensitizing antigens was measured after aerosol challenge with the antigen.

- Spinal cord injury in rats induced by 60 second clip compression of the spinal cord was measured by lesion site histology and histochemistry as well as recovery of locomotor function.

- Pancreatitis induced in mice by intravenous injection of caerulein was measured histologically, by determination of plasma amylase and lipase activity, and by immunoassays.

- In vitro and ex vivo studies on leukocyte migration, adhesion, cell surface marker expression, and reactive oxygen species production.

\section{Hypotension}

An early observation was that treatment with feG, like its predecessor SGP-T, inhibited the decrease in blood pressure associated with anaphylactic shock [38]. Challenge of sensitized rats with OA administered orally evoked a rapid drop in ventricular peak systolic pressure (VPSP) of 50 to $70 \mathrm{~mm} \mathrm{Hg}$. In normal rats or in unchallenged $O A$ sensitized rats intravenous administration of SGP-T, FEG, or feG had no effect on resting VPSP at any dosage. However, in OA challenged rats, intravenous administration of each of the peptides 10 minutes prior to challenge significantly protected against the drop in VPSP compared to saline treated controls. Importantly, oral administration of feG 20 minutes before OA challenge also produced a dose-dependent inhibition of cardiovascular shock (Figure 4).

\section{Leukocyte migration}

Neutrophil migration into carrageenan-soaked sponges 24 hours after subcutaneous implantation in rats was inhibited by intraperitoneal injection of $\mathrm{feG}$ at $100 \mu \mathrm{g} / \mathrm{kg}$ [39] (Figure 5). Neutrophil inflitration was significantly reduced by feG treatment in an acute pancreatitis model in mice [40] and also in a spinal cord injury model in rats [41].

Oral challenge in OA sensitized rats induces systemic effects including increased circulating leukocytes, leukocyte infiltration into the heart, increased vascular permeability, and pulmonary inflammation [42]. Changes in

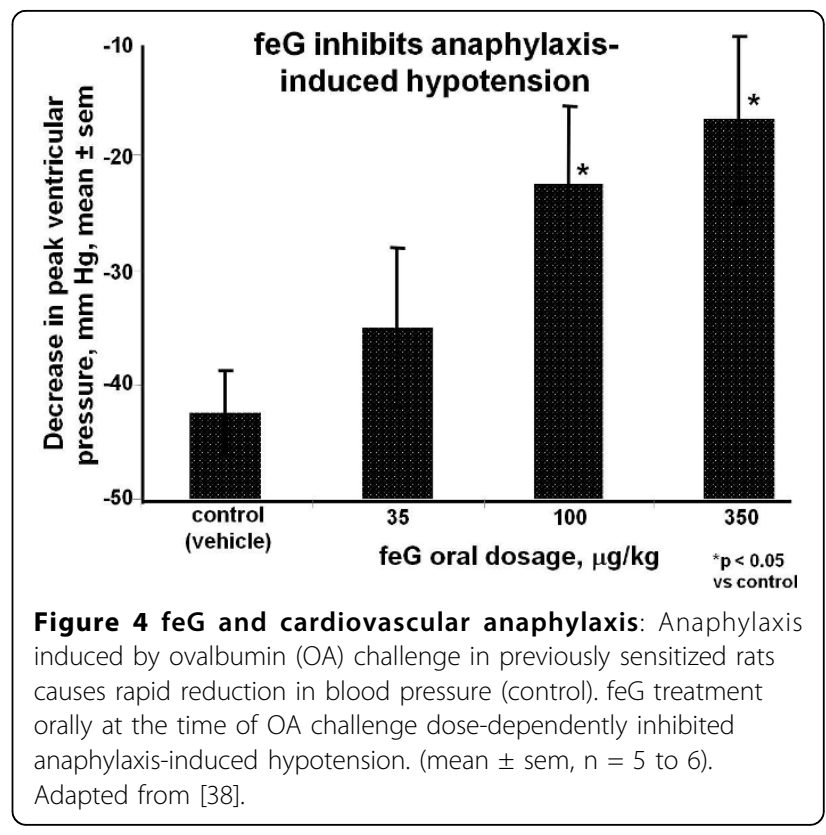

vascular permeability occurred within 30 minutes, peripheral blood neutrophilia appeared by 3 hours, and significant accumulation of neutrophils in the heart, detected by a $75 \%$ increase in myeloperoxidase (MPO) content, was seen at 24 hours after oral OA challenge. Treatment with feG intraperitoneally 20 minutes before antigen challenge significantly inhibited the increase in vascular permeability, circulating leukocytes and neutrophils, and neutrophil

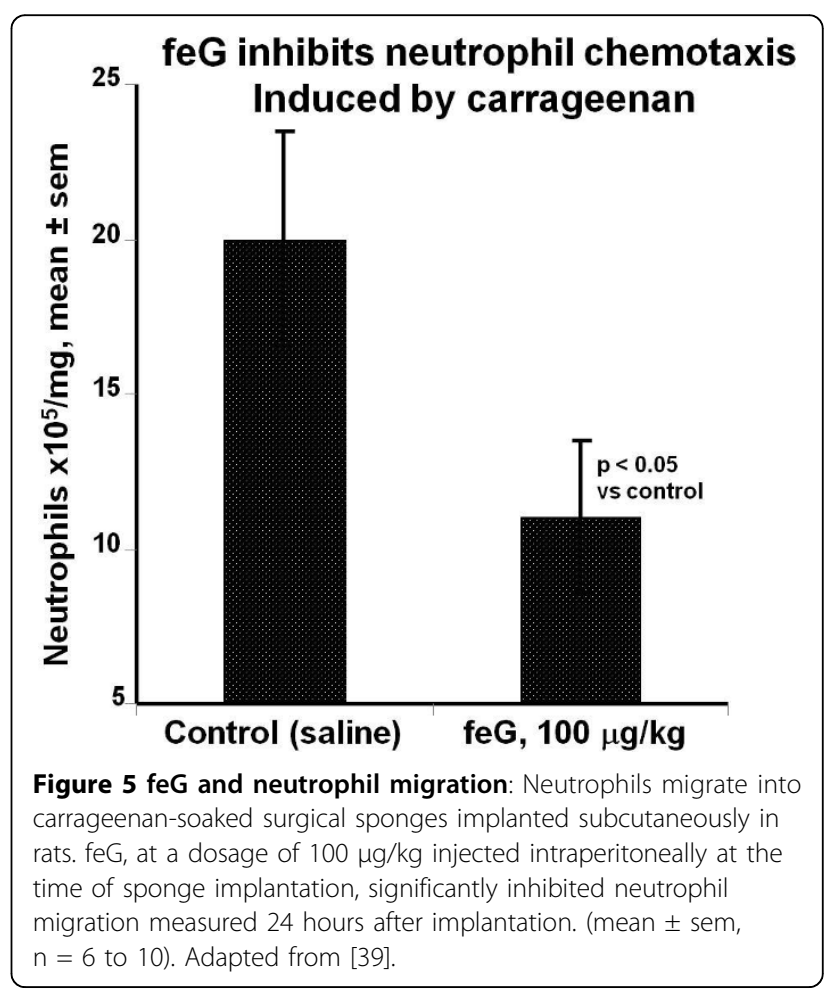


infiltration into the heart. Intraperitoneal injection of feG at $100 \mu \mathrm{g} / \mathrm{kg}$ at the time of oral OA challenge of sensitized rats almost completely inhibited the increase in circulating neutrophils detected 18 hours after challenge [43]. Pulmonary airway inflammation in OA sensitized rats was also inhibited by feG. Oral treatment with feG 30 minutes to 6 hours after oral OA challenge significantly inhibited neutrophil and eosinophil numbers in airways 24 hours after challenge [44] (Figure 6). In another study, oral treatment with feG at dosages of 250 and $1,000 \mu \mathrm{g} / \mathrm{kg} 30 \mathrm{~min}-$ utes before OA challenge inhibited influx of neutrophils, monocytes, and eosinophils into bronchoalveolar lavage fluid (BAL) but had no effect on lymphocytes [45].

Infusion of LPS in rats also causes accumulation of neutrophils in heart tissue in addition to acute hypotension [46]. Intravenous treatment with a carboxamide derivative, feG( $\left(\mathrm{NH}_{2}\right)$, at the time of LPS infusion, dosedependently inhibited accumulation of neutrophils in atrial slices 24 hours after intravenous LPS (Figure 7). Orally administered feG $(100 \mu \mathrm{g} / \mathrm{kg})$ also significantly reduced the number of macrophages and neutrophils recovered in peritoneal lavage fluid 24 hours after LPS challenge [47].

\section{Intestinal effects}

Oral challenge with OA in sensitized rats also results in disrupted intrinsic rhythmicity MMCs in the small intestine, and in diarrhea in $85 \%$ of challenged animals $[38,48]$. Oral dosage of $\mathrm{feG}$ at $350 \mu \mathrm{g} / \mathrm{kg}$ at the time of OA challenge totally abolished the intestinal anaphylactic reaction and diarrhea in all rats tested. In a similar study feG given orally 30 minutes before OA challenge dose dependently inhibited anaphylaxis-induced intestinal motility, with maximal inhibition achieved at the

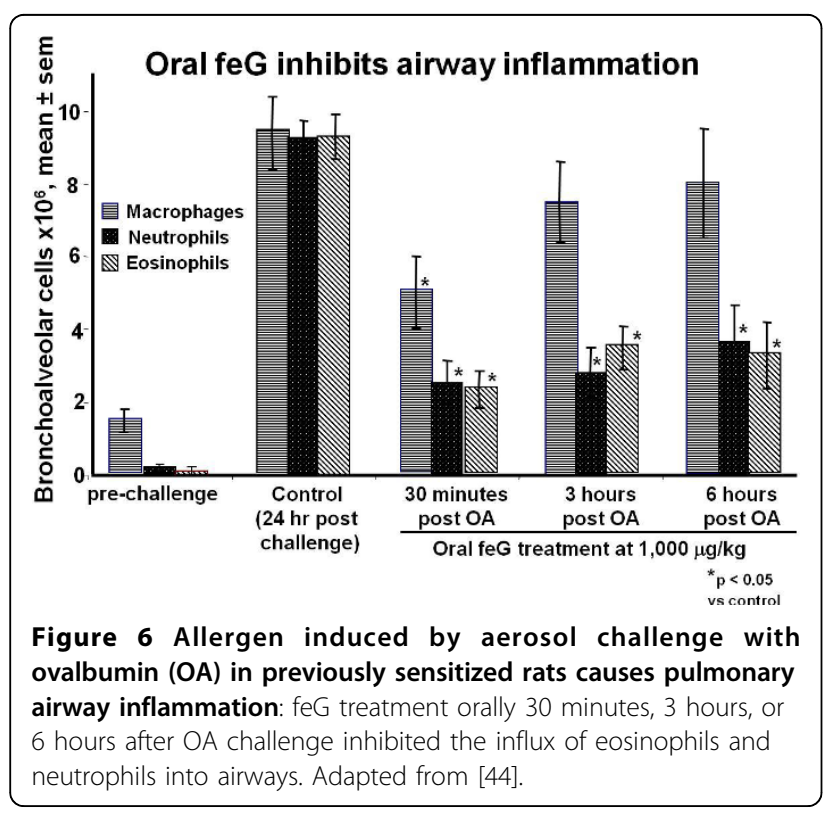

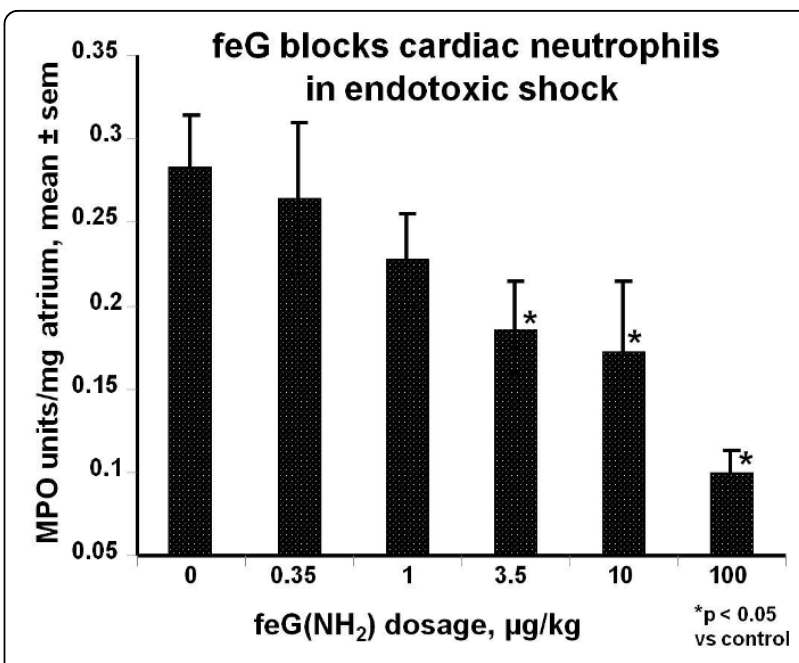

Figure 7 Neutrophil accumulation in heart tissue: Intravenous administration of lipopolysaccharide (LPS) in rats causes accumulation of neutrophils in heart tissue as detected by myeloperoxidase (MPO) activity in atrial slices 24 hours after LPS infusion. Intravenous treatment with a carboxamide derivative, feG $\left(\mathrm{NH}_{2}\right)$, at the time of LPS infusion, dose-dependently inhibited MPO in atrial slices. (mean \pm sem, $n=4$ to 8). Adapted from [46].

highest dosage-100 $\mu \mathrm{g} / \mathrm{kg}$ [49]. Interestingly, feG dosage $(100 \mu \mathrm{g} / \mathrm{kg})$ up to 8 hours before challenge afforded significant protection against intestinal anaphylaxis, suggesting a long biological half life (Figure 8) [49].

Infusion of LPS in rats also has acute effects on the intestine by disrupting the standard MMCs and produces a pattern of intense, irregular myoelectricity [50]

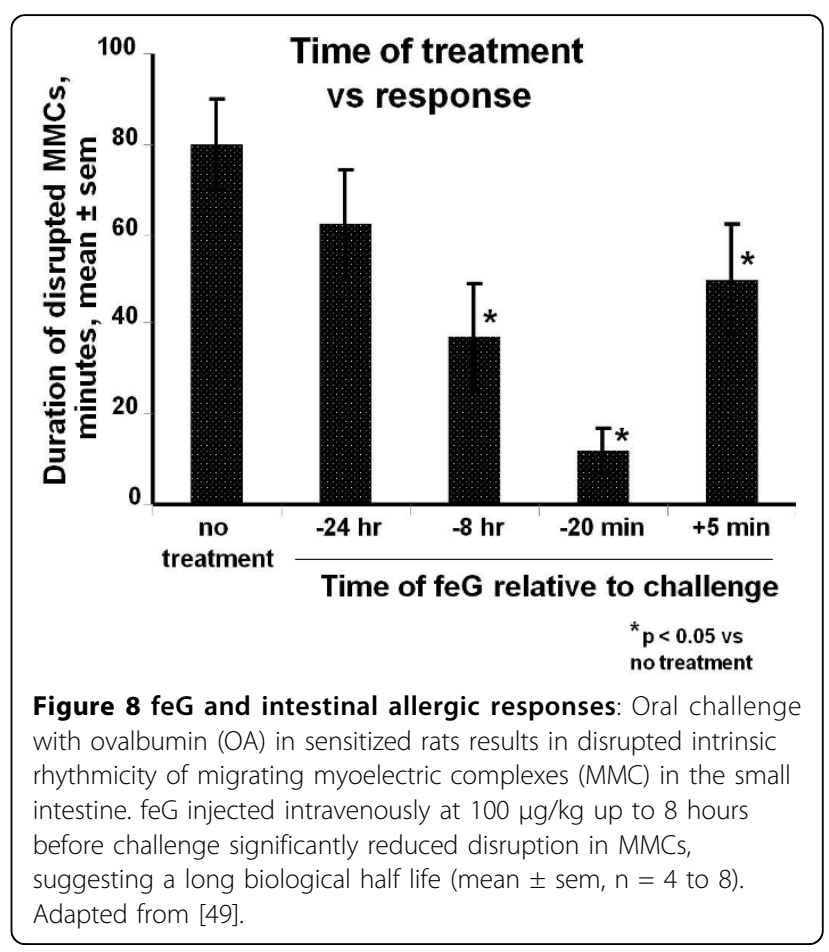


Intravenous injection of feG 20 minutes before LPS dose-dependently reduced the length of time of disruption of jejunal MMCs. Interestingly, the carboxamide derivative, feG $\left(\mathrm{NH}_{2}\right)$, was found to be more potent than feG in this endotoxemia model. feG given orally 20 minutes before LPS challenge inhibited disruption of MMCs in a bell shaped, dose-dependent manner, with $65 \mu \mathrm{g} / \mathrm{kg}$ providing maximal inhibition.

\section{Effects on pulmonary inflammation and function}

Effects of feG treatment were further studied in pulmonary inflammation models in rats sensitized with either OA or with larvae of Nippostrongylis braziliensis $(\mathrm{Nb})$ and challenged by aerosol administration of the sensitizing antigens [45], Oral treatment with feG at 1 $\mathrm{mg} / \mathrm{kg} 30$ minutes prior to OA challenge significantly reduced airway hyper-responsiveness to methacholine measured 24 hours after challenge. In Nb sensitized rats feG significantly reduced tracheal smooth muscle contraction in response to aerosol $\mathrm{Nb}$ challenge.

In asthmatic sheep naturally sensitized to Ascaris suum, bronchoconstriction, determined by measuring specific lung resistance (SRL), and airway hyperresponsiveness to carbachol were measured in instrumented sheep after aerosol challenge with the antigen [51]. Bronchoconstriction (SRL) increased rapidly up to $500 \%$ immediately after aerosol challenge, decreased to baseline values over 3 hours, but was followed by a secondary increase in SRL 5 hours after challenge. Treatment with feG intravenously $(1 \mathrm{mg} / \mathrm{kg}$ ) or orally $(2 \mathrm{mg} /$ $\mathrm{kg}$ ) had no effect on the early, acute phase increase in SRL, but inhibited the late phase increase by $72 \%$ and $78 \%$ respectively relative to challenged untreated controls (Figure 9). Inhaled feG, at a dose of $30 \mathrm{mg} / \mathrm{sheep}$, reduced early (by $83 \%$ ) as well late (by $88 \%$ ) bronchoconstriction. Airway hyper-responsiveness to carbachol, measured 24 hours after antigen challenge, was significantly inhibited by pre-challenge treatment with feG intravenously, orally, or by aerosol delivery.

In cats sensitized to Bermuda grass allergen, administration of feG orally at $1 \mathrm{mg} / \mathrm{kg}$ immediately prior to allergen challenge resulted in a significant reduction in accumulation of eosinophils in bronchoalveolar lavage fluid [52]. However, daily treatment for 2 weeks in experimentally asthmatic cats had no measurable effect on airway inflammation [53]. This latter result suggests that further studies will be necessary to evaluate dosing regimens and formulation for feG (see Pharmacodynamic/pharmacokinetic considerations below).

\section{Vascular Permeability}

The effects of feG on vascular permeability induced by antigen challenge and histamine have been studied in both rats and dogs. With both species intradermal injection of feG $\left(10^{-6} \mathrm{M}\right.$ to $\left.10^{-9} \mathrm{M}\right)$ significantly reduced the

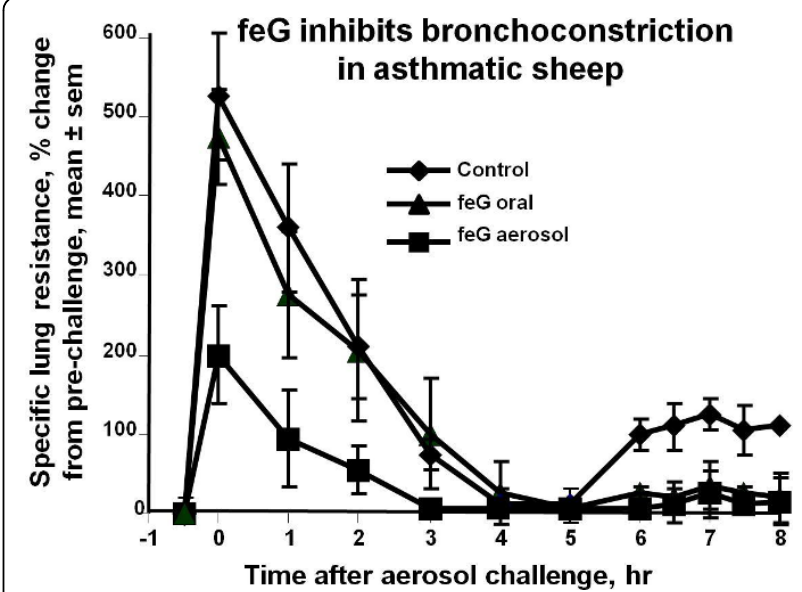

Figure 9 feG and asthma in sheep: In asthmatic sheep naturally sensitized to Ascaris suum, bronchoconstriction determined by measuring specific lung resistance $\left(S R_{L}\right)$ increased rapidly immediately after aerosol challenge, decreased to baseline values over 4 hours, but was followed by a secondary increase in $\mathrm{SR}_{\mathrm{L}} 5$ after hours post challenge. Inhaled feG at a dose of $30 \mathrm{mg} / \mathrm{sheep}$ reduced early as well as late increases in $\mathrm{SR}_{\mathrm{L}}$, whereas treatment with feG intravenously ( $1 \mathrm{mg} / \mathrm{kg}$ ) or orally $(2 \mathrm{mg} / \mathrm{kg}$ ) inhibited only late phase bronchoconstriction. (mean \pm sem, $n=4$ to 8). Adapted from [51].

increase in vascular leak of a dye (Evans blue) provoked by both active cutaneous anaphylaxis and histamine by up to $40 \%$ at high doses to $\sim 20 \%$ at lower doses (unpublished observations).

\section{Other disease models: acute pancreatitis, spinal cord injury}

In acute pancreatitis, induced in mice by 12 hourly injections of caerulein, a single dose of feG $(100 \mu \mathrm{g} / \mathrm{kg})$ was administered intraperitoneally at induction (prophylactic) or 3 hours post induction (therapeutic) [40]. Plasma lipase activity was reduced in feG groups treated both prophylactically and therapeutically; amylase was reduced in feG groups treated prophylactically (Figure 10). Histologically, feG treatment reduced pancreatitisinduced edema and acinar cell necrosis.

In a clip compression model of spinal cord injury in rats, leukocyte infiltration, free radical formation, and oxidative damage at the lesion site were quantified [41]. Neutrophil infiltration, detected by MPO activity, and activated phagocytic macrophages, identified by ED-1 expression, were present within 24 hours of injury. Intravenous feG treatment 2, 6, or 12 hours after injury reduced MPO activity, ED-1 expression, oxidative enzymes, free radical production, lipid peroxidation, and cell death (caspase-3 expression) in injured cord lesion sites. These anti-inflammatory and anti-oxidative actions of feG treatment correlated with improved neurological outcomes after spinal cord injury. In a similar spinal 


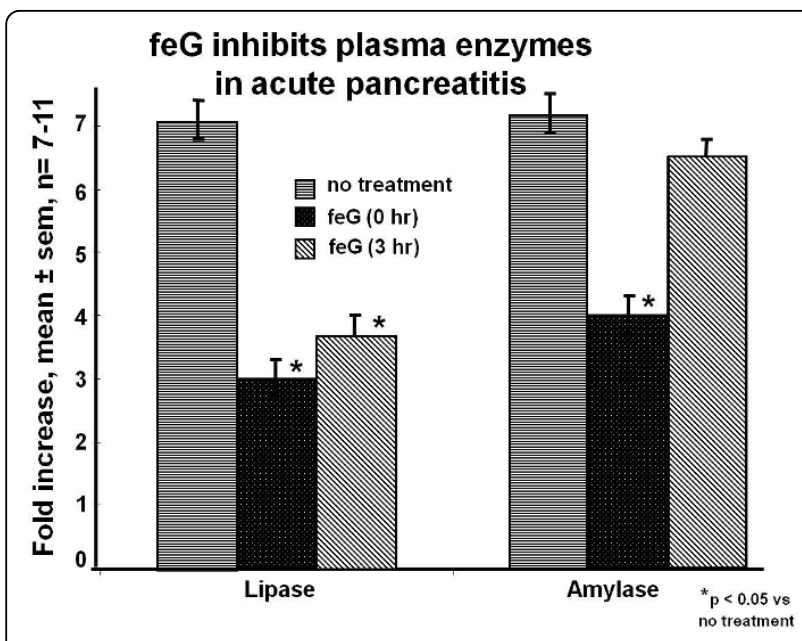

Figure 10 feG and acute pancreatitis. In acute pancreatitis, induced in mice by 12 hourly injections of caerulein, a single intraperitoneal dose of feG $(100 \mu \mathrm{g} / \mathrm{kg})$ administered at start of caerulein induction or 3 hours after start of induction, inhibited plasma lipase and amylase activity. Adapted from [40].

cord injury model feG given intravenously at $200 \mu \mathrm{g} / \mathrm{kg}$ twice daily for 5 days improved locomotor and allodynia scores relative to controls over 7 weeks following cord injury [54] (Figure 11).

\section{Pharmacodynamic/pharmacokinetic considerations}

From a pharmacodynamic perspective, it appears that feG has a long biological half life. Single intravenous dosages of feG inhibit endotoxin-provoked accumulation of neutrophils in cardiac tissue for at least 24 hours [46] (see Figure 7). Single oral dosage of feG in OA sensitized challenged rats also inhibits neutrophil and

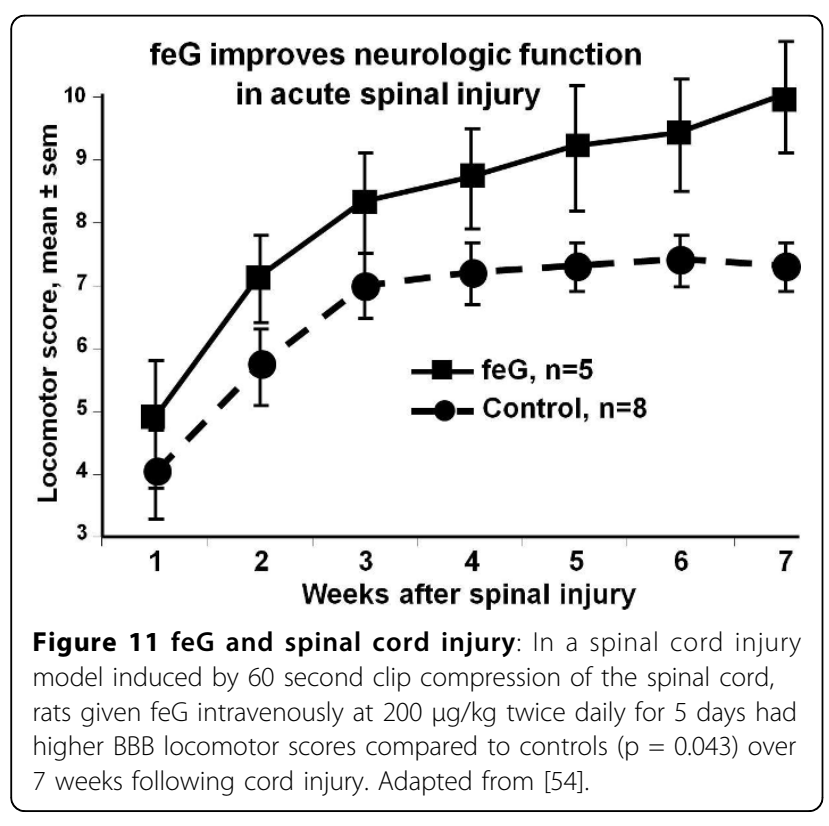

eosinophil migration into airways for at least 24 hours [44] (see Figure 6). Likewise in asthmatic sheep intravenous, oral, or aerosol administration of feG blocks airway responsiveness for at least 24 hours after antigen challenge [51].

Bell shaped dose-response relationships were observed in various assays, so frequently as to not be dismissible as coincidental. First observed with SGP-T inhibition of anaphylaxis-induced hypotension in rats [55] and inhibition of neutrophil migration into carrageenan soaked sponges [22] (see Figure 5), feG treatment also resulted in a biphasic dose-response curve in an intestinal endotoxemia model [38]. In vitro incubation of human neutrophils with feG within a window of molar concentrations between $10^{-11}$ to $10^{-9} \mathrm{M}$ down regulated platelet activating factor- (PAF) induced expression of CD 11b (AlphaM integrin chain) and PAF-induced neutrophil migration [39] (Figure 12). Within these same molar concentrations feG inhibited fibrinogen and fibronectin binding of peritoneal leukocytes from rats that had been infused with LPS 18 hours earlier. Binding of leukocytes from LPS treated rats to atrial slices was inhibited by feG in vitro at concentrations of $10^{-9} \mathrm{M}$ but not $10^{-7} \mathrm{M}$ [46]. These findings suggest that dosage of feG may be critical to achieve the desired therapeutic effect.

Pharmacokinetic studies, to our knowledge, have not been performed on feG in any species. However, results of preliminary pharmacokinetic and toxicokinetic studies have been performed on a closely-related salivary tripeptide (D-cyclohexylalanine-D-glutamate-glycine; (cha)eG) in rats, dogs, and monkeys (proprietary, in-house data, 2010). In rats and dogs oral dosages of $2,500 \mu \mathrm{g} / \mathrm{kg}$ of

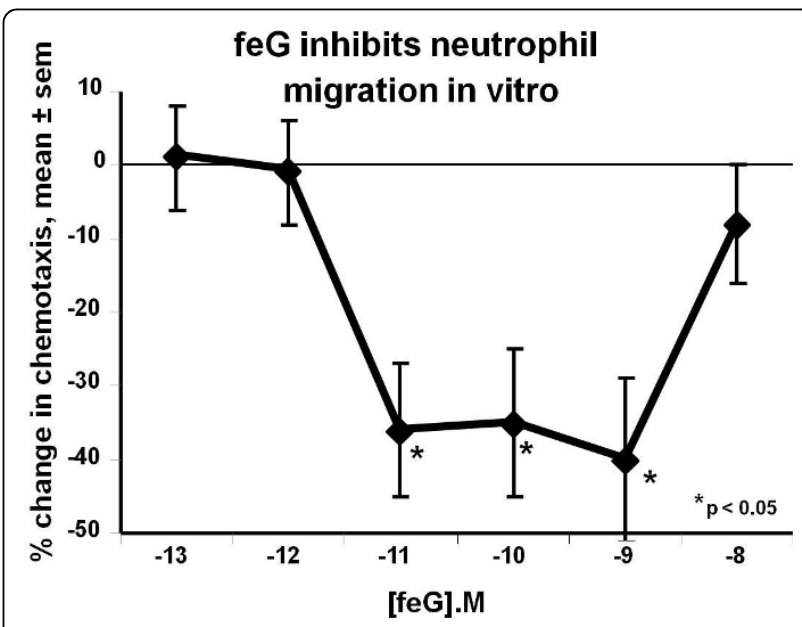

Figure 12 feG and human neutrophils: Incubation of human neutrophils with feG within a window of molar concentrations between $10^{-11}$ to $10^{-9} \mathrm{M}$ downregulated platelet activating factor(PAF) induced neutrophil migration in vitro. (mean \pm sem, $n=3$ to 7). Adapted from [39]. 
(cha)eG were required to achieve detectable plasma concentrations $(>5 \mathrm{ng} / \mathrm{mL})$. Oral bioavailability was estimated to be less than $1 \%$ in the rat. In monkeys detectable plasma levels of (cha)eG persisted for 24 hours following a single intravenous dosage of $10 \mathrm{mg} /$ $\mathrm{kg}$, with an apparent terminal half life of approximately 9 hours, consistent with pharmacodynamic findings in rats (see Figure 8). However, noting that in vitro feG is active within a window of concentrations of about 0.0035 to $0.35 \mathrm{ng} / \mathrm{mL}$, and that in model studies in rats feG dosage of $100 \mu \mathrm{g} / \mathrm{kg}$ was consistently found to be effective regardless of route of administration, it must be concluded that the systemic bioactivity of feG occurs at concentrations well below minimum detectable plasma concentrations of current assays. In other words, the dosage riddle is unlikely to be solved by pharmacokinetics.

\section{Mechanism studies: Effect of feG on neutrophil chemotaxis, adhesion, and function}

Results of in vivo studies point to the neutrophil as the primary target cell for the immunopharmacologic actions of feG and other bioactive factors produced by the salivary gland. Early results showed that SGP-T treatment inhibited neutrophil chemotaxis [22] as well as rolling [23].

\section{Effect on adhesion}

In peritoneal neutrophils collected from OA sensitized rats 24 hours after challenge, pre-treatment with feG had no effect on expression of the alpha integrin CD $11 \mathrm{~b}$ but down regulated expression of the beta 1 integrin CD49 d (Alpha-4 integrin chain) [42]. In vitro incubation of human neutrophils with feG inhibited PAF induced neutrophil migration (see Figure 12) as well as expression of CD 11b [39]. In normal (unstimulated) neutrophils feG had no effect on neutrophil adhesion to gelatin, whereas in PAF-activated cells feG at $10^{-11}$ and $10^{-10} \mathrm{M}$ significantly inhibited adhesion of human neutrophils. However, within molar concentrations of $10^{-11}$ to $10^{-9} \mathrm{M}$, feG had no effect on PAF-stimulated superoxide release or on phagocytotic activity, suggesting that feG modulates primarily neutrophil adhesion and migratory responses. Peritoneal neutrophils from OA sensitized rats 24 hours after challenge were also tested for expression of CD11b and CD16b (Fc-gamma RIIIb: Low affinity immunoglobulin gamma $\mathrm{Fc}$ region receptor IIIB). feG treatment (100 $\mu \mathrm{g} / \mathrm{kg}$ orally) inhibited CD $11 \mathrm{~b}$ antibody binding to peritoneal neutrophils in unchallenged but not in OA challenged rats. CD 16b binding, however, was inhibited by feG treatment in both challenged and unchallenged rats. In vitro (microtiter plates) feG inhibits adhesion of rat peritoneal leukocytes, but only if the cells were stimulated with PAF[43], indicating

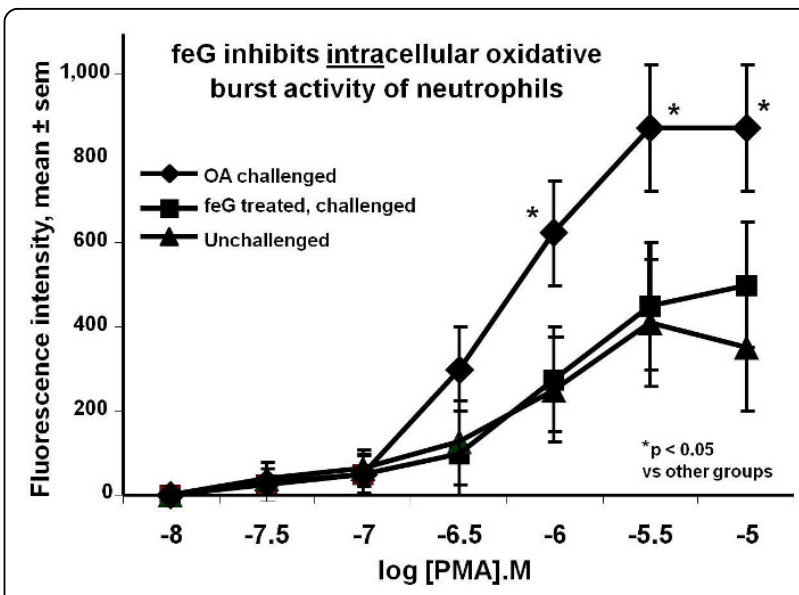

Figure 13 feG and the oxidative burst: - Dose-response for phorbol myristate acetate- (PMA) stimulated intracellular oxidative activity of circulating neutrophils 18 hours after ovalbumin (OA) challenge in $\mathrm{OA}$ sensitized rats. feG was injected intraperitoneally at $100 \mathrm{\mu g} / \mathrm{kg}$ at the time of challenge. Oxidative activity was measured using flow cytometry for a marker of oxygen free radicals, 123-

dihydrorhodamine. (mean \pm sem, $n=6$ to 7). Adapted from [57].

that feG's actions require cell activation. feG treatment also completely blocked the expression of the beta 1-integrin CD49 d on circulating neutrophils which was up regulated by $O A$ challenge, but had no effect on CD11b expression. These and other findings led to the conclusion, that when administered in vivo feG prevents inflammation-induced reduction in cell adhesion as well as restoring its inhibitory effect in vitro.

\section{Effect on oxidative activity}

Neutrophils, which play a key role in the development and perpetuation SIRS, inactivate and destroy virulent pathogens through the release of superoxide and enzymes and by phagocytosis [56]. In OA sensitized rats the extracellular release of superoxide anion by circulating neutrophils 18 hours after OA challenge was not modified by either OA challenge or feG treatment [57], confirming similar findings in previous studies [39]. However, incubation of the cells with phorbol myristate acetate (PMA), a protein kinase C (PKC) activator, increased intracellular release of reactive oxygen species as determined by flow cytometry for a marker of oxygen free radicals, 123-dihydrorhodamine. feG treatment at the time of challenge inhibited intracellular superoxide production by PMA-stimulated blood neutrophils 18 hours after challenge (Figure 13). These findings led to the speculation that feG reduces the capacity of neutrophils to generate reactive oxygen species by preventing the deregulation of PKC consequent to an allergic reaction.

Saliva, in addition to its role as a digestive aid, contributes significantly to lubrication, protection, defence and 
wound healing in the mouth. The importance of salivary glands and their secretions are poorly appreciated, and they are only taken seriously when salivary gland dysfunction results in decreased saliva flow. In humans this dysfunction contributes to difficulties in tasting, eating, swallowing, and speaking, and results in sores of the soft tissues of the mouth and periodontal disease. These pathologies also manifest in human patients with a variety of systemic diseases including - Sjögren's syndrome, rheumatoid arthritis, juvenile idiopathic (rheumatoid) arthritis, systemic lupus erythematosus (an inflammatory connective tissue disease), systemic sclerosis (sceloderma), primary bilary cirrhosis (an autoimmune disease of the liver), sarcidosis (a multisystem granulomatous disorder), infections with human immunodeficiency virus, herpes virus, hepatitis $\mathrm{C}$, ectodermal dysplasia, chronic pancreatitis and depression [58].

Nonetheless, it should be recognized that the relationship between salivary glands and systemic health is bidirectional. "Oral infection may represent a significant risk-factor for systemic diseases, and hence the control of oral disease is essential in the prevention and management of these systemic conditions" [59]. Chronic inflammatory periodontal diseases are among the most prevalent chronic infections in humans, and many investigators have established a significant, albeit modest, positive association between periodontal disease and cardiovascular disease, which includes atherosclerosis, myocardial infarction and stroke. In addition, epidemiological associations have been made between periodontal diseases and chronic diseases such as diabetes, respiratory diseases and osteoporosis [60].

Likewise in veterinary medicine epidemiologic studies reveal that oral disease is the most common disease in all age groups of dogs and cats [61]. Moreover, there is evidence that oral infection also has systemic effects including renal, hepatic, pulmonary, and cardiac diseases; osteoporosis, adverse pregnancy effects, and diabetes mellitus [62], and can lead to systemic inflammation [63]. The severity of periodontal disease was found to be positively correlated with histological changes in kidneys, myocardium, and liver [64].

In this review we focused on SGP-T and its derivatives namely FEG and its D-isomeric derivative feG, which in themselves demonstrate the significant physiological and immunological modulation exerted by salivary gland peptides. These peptides have significant anti-inflammatory actions, as shown in animal models of endotoxic shock (Figures 1 \&7), allergic and anaphylactic reactions (Figures 4, 6, 8 \&9), pancreatic (Figure 10) and spinal cord injury (Figure 11).

feG, and its analogues, exhibit a distinctly different mechanism of anti-inflammatory action from corticosteroids and nonsteroidal anti-inflammatory drugs (NSAIDs). NSAIDs and corticosteroids have become the mainstay of anti-inflammatory agents in human and veterinary medicine. NSAIDs are popular owing to their immune sparing effect, especially since the discovery that they act by inhibiting cyclooxygenase (COX), an enzyme that catalyses the arachidonic acid cascade resulting in production of pro-inflammatory eicosanoids [65]. In contrast to enzymatic blockade, the tripeptide feG has multimodal activity and acts directly on activated leukocytes, specifically down regulating expression of integrins, thereby inhibiting chemotaxis (Figures 2 \&12) and cell migration (Figure 5). Furthermore, feG inhibits the function of neutrophils by specifically inhibiting intracellular superoxide production by activated neutrophils (Figure 13), probably as a consequence of interruption of the signaling cascade that induces superoxide generation [66].

Hence feG and its analogues appear to represent a new class of anti-inflammatory agents which act on immune cells, the central regulators of all inflammation. The term "Immune Selective Anti-Inflammatory Derivatives" (ImSAIDs) is proposed for salivary-derived peptides to distinguish this class of agents from corticosteroids and NSAIDs. A closely-related salivary tripeptide ((cha)eG) is currently under investigation as an anti-asthmatic therapeutic in humans.

\section{Conclusions}

Based on its mechanism of action and demonstrable in vivo pharmacologic activity, feG deserves evaluation in a number of situations characterized by over-exuberant or chronic inflammatory responses of human and veterinary significance associated with several major organ systems:

- Whole body and circulatory: sepsis, endotoxemia, SIRS [67];

- Gastrointestinal: pancreatitis, hepatitis, gastroenteritis, enteritis;

- Oral cavity: stomatitis

- Respiratory: asthma, acute pulmonary inflammation of diverse etiologies;

- Musculo-Skeletal: fibromyalgia, rheumatoid arthritis, equine laminitis (now characterized as a neutrophil-mediated inflammatory disease [68]);

- Nervous: spinal cord injury, peripheral nerve injury;

- Urinary tract: cystitis

Aside from these therapeutic potentials, feG may eventually prove to be useful as a vetraceutical or a nutraceutical [the term coined by Stephen DeFelice 
[69]] to reduce the incidence and severity of systemic and localized inflammations caused by intense exercise, poor oral health and other causes.

\section{List of Abbreviations}

BAL: bronchoalveolar lavage fluid; CD11b: AlphaM integrin chain; CD16b: Fcgamma Rlllb - Low affinity immunoglobulin gamma Fc region receptor IIIB: CD49 d: Alpha-4 integrin chain; (cha)eG: D-cyclohexylalanine-D-glutamateglycine COX: cyclooxygenase; FEG: Phenylalanine-Glutamate-Glycine; feG: Dphenylalanine-D-glutamate-Glycine; IgE: immunoglobulin E; ImSAIDs: Immune Selective Anti-Inflammatory Derivatives; LPS: lipopoylsaccharide; MMC: migrating myoelectric complexes; MPO: myeloperoxidase; $\mathrm{Nb}$ : Nippostrongylus brasiliensis; NSAID: non steroidal anti-inflammatory drugs; OA: ovalbumin; PAF: platelet activating factor; PKC: protein kinase C; PMA: phorbol myristate acetate; SGP-T: submandibular peptide-T; SIRS: systemic inflammatory response syndrome; SRL: specific lung resistance; SMR1: submandibular rat-1; VCS-1: variable coding sequence-1; VPSP: ventricular peak systolic pressure

\section{Competing interests}

DAG is a research veterinarian and a minority shareholder in a company which has commercial rights to salivary-derived peptides for veterinary use. RM and JSD have shares in a privately held company that is developing peptides and their analogues for therapeutic use.

\section{Authors' contributions}

DAG conducted the literature search, wrote the first draft of the manuscript, and composed and edited the figures. RM contributed literature searches and the rewriting and editing. JSD and ADB provided important discussion and editorial comments. All authors read and approved the final manuscript.

\section{Acknowledgements}

The financial assistance of Allergen NCE Inc. is gratefully acknowledged.

\section{Author details}

'Faculty of Medicine, University of Calgary, 3330 Hospital Drive NW, Calgary, Alberta, T2N 4N1, Canada. ${ }^{2} 550$ A Heritage Medical Research Centre, Faculty of Medicine and Dentistry, University of Alberta, Edmonton, Alberta, T6G 2S2, Canada. ${ }^{3}$ Turtle Creek Biostatistical Consulting, 2219 Wilmington Road, Lebanon, $\mathrm{OH}$ 45036, USA.

Received: 19 August 2010 Accepted: 28 September 2010

Published: 28 September 2010

\section{References}

1. Pedersen AM, Bardow A, Jensen SB, Nauntofte B: Saliva and gastrointestinal functions of taste, mastication, swallowing and digestion. Oral Dis 2002, 8:117-129.

2. Tenovuo J: Antimicrobial agents in saliva - protection for the whole body. Journal of Dental Research 2002, 81:807-809.

3. Barka T: Biologically active polypeptides in submandibular glands. Histochem Cytochem 1980, 28:836-859.

4. Rougeot C, Messaoudi M, Hermitte V, Rigault AG, Blisnick T, Dugave C, Desor D, Rougeon F: Sialorphin, a natural inhibitor of rat membranebound neutral endopeptidase that displays analgesic activity. Proc Natl Acad Sci USA 2003, 100:8549-8554.

5. Isenman L, Liebow C, Rothman S: The endocrine secretion of mammalian digestive enzymes by exocrine glands. Am J Physiol 1999, 276:E223-232.

6. Kongshavn PA, Lapp WS: Immunosuppressive effect of male mouse submandibular gland extracts on plaque-forming cells in mice: abolition by orchiectomy. Immunology 1972, 22:227-230.

7. Kemp A, Mellow L, Sabbadini E: Suppression and enhancement of in vitro lymphocyte reactivity by factors in rat submandibular gland extracts. Immunology 1985, 56:261-267.

8. Amico-Roxas M, Caruso A, Leone MG, Scifo R, Vanella A, Scapagnini U: Nerve growth factor inhibits some acute experimental inflammations. Arch Int Pharmacodyn Ther 1989, 299:269-285.
9. Mathison R, Davison JS, Befus AD: Neuroendocrine regulation of inflammation and tissue repair by submandibular gland factors. Immunol Today 1994, 15:527-532.

10. Felten DL, Felten SY, Bellinger DL, Carlson SL, Ackerman KD, Madden KS, Olschowki JA, Livnat S: Noradrenergic sympathetic neural interactions with the immune system: structure and function. Immunol Rev 1987, 100:225-260.

11. Nance DM, Hopkins DA, Bieger D: Re-investigation of the innervation of the thymus gland in mice and rats. Brain Behav Immun 1987, 1:134-147.

12. Madden KS, Felten SY, Felten DL, Sundaresan PR, Livnat S: Sympathetic neural modulation of the immune system. I. Depression of T cell immunity in vivo and vitro following chemical sympathectomy. Brain Behav Immun 1989, 3:72-89.

13. Alito AE, Romeo HE, Baler R, Chuluyan HE, Braun M, Cardinali DP: Autonomic nervous system regulation of murine immune responses as assessed by local surgical sympathetic and parasympathetic denervation. Acta Physiol Pharmacol Latinoam 1987, 37:305-319.

14. Ramaswamy K, Mathison R, Carter L, Kirk D, Green F, Davison JS, Befus D: Marked antiinflammatory effects of decentralization of the superior cervical ganglia. J Exp Med 1990, 172:1819-1830.

15. Mathison R, Hogan A, Helmer D, Bauce L, Woolner J, Davison JS, Schultz G, Befus D: Role for the submandibular gland in modulating pulmonary inflammation following induction of systemic anaphylaxis. Brain Behav Immun 1992, 6:117-129.

16. Mathison R, Befus D, Davison JS: Removal of the submandibular glands increases the acute hypotensive response to endotoxin. Circ Shock 1993, 39:52-58.

17. Mathison $\mathrm{RD}$, Befus $\mathrm{AD}$, Davison JS: A novel submandibular gland peptide protects against endotoxic and anaphylactic shock. Am J Physiol 1997, 273:R1017-1023

18. Rosinski-Chupin I, Tronik D, Rougeon F: High level of accumulation of a mRNA coding for a precursor-like protein in the submaxillary gland of male rats. Proc Natl Acad Sci USA 1988, 85:8553-8557.

19. Morris KE, St Laurent CD, Hoeve RS, Forsythe $P$, Suresh MR, Mathison RD, Befus AD: Autonomic nervous system regulates secretion of antiinflammatory prohormone SMR1 from rat salivary glands. Am J Physiol Cell Physiol 2009, 296:C514-524.

20. Mathison R, Tan D, Oliver M, Befus D, Scott B, Davison JS: Submandibular gland peptide-T (SGP-T) inhibits intestinal anaphylaxis. Dig Dis Sci 1997, 42:2378-2383.

21. Mathison RD, Malkinson T, Cooper KE, Davison JS: Submandibular glands: novel structures participating in thermoregulatory responses. Can $J$ Physiol Pharmacol 1997, 75:407-413.

22. Nkemdirim $M$, Kubera M, Mathison R: Modulation of neutrophil activity by submandibular gland peptide-T (SGP-T). Pol J Pharmacol 1998, 50:417-424

23. Mathison RD, Sank C, Davison JS: Inhibition of leukocyte rolling by submandibular gland peptide-T (SGP-T). Proc West Pharmacol Soc 1999, 42:39-40.

24. Morris K, Kuo B, Wilkinson MD, Davison JS, Befus AD, Mathison RD: Vcsa1 gene peptides for the treatment of inflammatory and allergic reactions. Recent Pat Inflamm Allergy Drug Discov 2007, 1:124-132.

25. Rosinski-Chupin I, Kuramoto T, Courty Y, Rougeon F, Serikawa T: Assignment of the rat variable coding sequence (VCS) gene family to chromosome 14. Mamm Genome 1995, 6:153-154.

26. Rosinski-Chupin I, Rougeon F: The gene encoding SMR1, a precursor-like polypeptide of the male rat submaxillary gland, has the same organization as the preprothyrotropin-releasing hormone gene. DNA Cell Biol 1990, 9:553-559.

27. Rougeot C, Rosinski-Chupin I, Rougeon F: Novel genes and hormones in salivary glands: From the gene for the submandibular rat1 protein (SMR1) precursor to receptor sites for SMR1 mature peptides. Biomedical Reviews 1998, 9:17-32.

28. Dickinson DP, Thiesse M: cDNA cloning of an abundant human lacrimal gland mRNA encoding a novel tear protein. Curr Eye Res 1996, 15:377-386.

29. Isemura S: Nucleotide sequence of gene PBII encoding salivary prolinerich protein P-B. J Biochem (Tokyo) 2000, 127:393-398.

30. Isemura $\mathrm{S}$, Saitoh E: Nucleotide sequence of gene PBI encoding a protein homologous to salivary proline-rich protein P-B. J Biochem (Tokyo) 1997, 121:1025-1030. 
31. Wisner A, Dufour E, Messaoudi M, Nejdi A, Marcel A, Ungeheuer MN, Rougeot C: Human Opiorphin, a natural antinociceptive modulator of opioid-dependent pathways. Proc Natl Acad Sci USA 2006, 103:17979-17984.

32. Davies KP, Tar M, Rougeot C, Melman A: Sialorphin (the mature peptide product of Vcsa1) relaxes corporal smooth muscle tissue and increases erectile function in the ageing rat. BJU Int 2007, 99:431-435.

33. Messaoudi M, Desor D, Nejdi A, Rougeot C: The endogenous androgenregulated sialorphin modulates male rat sexual behavior. Horm Behav 2004, 46:684-691.

34. Tong Y, Tar M, Davelman F, Christ G, Melman A, Davies KP: Variable coding sequence protein $\mathrm{A} 1$ as a marker for erectile dysfunction. BJU Int 2006, 98:396-401.

35. Davies KP: The role of opiorphins (endogenous neutral endopeptidase inhibitors) in urogenital smooth muscle biology. J Sex Med 2009, 6(Suppl 3):286-291.

36. Rosinski-Chupin I, Huaulme JF, Rougeot C, Rougeon F: The transcriptional response to androgens of the rat VCSA1 gene is amplified by both binary and graded mechanisms. Endocrinology 2001, 142:4550-4559.

37. Tong Y, Tar M, Melman A, Davies K: The opiorphin gene (ProL1) and its homologues function in erectile physiology. BJU Int 2008, 102:736-740.

38. Mathison R, Lo P, Moore G, Scott B, Davison JS: Attenuation of intestinal and cardiovascular anaphylaxis by the salivary gland tripeptide FEG and its D-isomeric analog feG. Peptides 1998, 19:1037-1042.

39. Mathison RD, Befus AD, Davison JS, Woodman RC: Modulation of neutrophil function by the tripeptide feG. BMC Immunol 2003, 4:3.

40. Rifai Y, Elder AS, Carati CJ, Hussey DJ, Li X, Woods CM, Schloithe AC, Thomas AC, Mathison RD, Davison JS, Toouli J, Saccone GT: The tripeptide analog feG ameliorates severity of acute pancreatitis in a caerulein mouse model. Am J Physiol Gastrointest Liver Physiol 2008, 294:G1094-1099.

41. Bao F, John SM, Chen Y, Mathison RD, Weaver LC: The tripeptide phenylalanine-(d) glutamate-(d) glycine modulates leukocyte infiltration and oxidative damage in rat injured spinal cord. Neuroscience 2006, 140:1011-1022.

42. Turesin F, Sadr A, Davison JS, Mathison R: The tripeptide FEG ameliorates systemic inflammatory responses to rat intestinal anaphylaxis. $B M C$ Physiol 2002, 2:13.

43. Mathison RD, Christie E, Davison JS: The tripeptide feG inhibits leukocyte adhesion. J Inflamm (Lond) 2008, 5:6.

44. Dery RE, Mathison R, Davison J, Befus AD: Inhibition of allergic inflammation by C-terminal peptides of the prohormone submandibular rat 1 (SMR-1). Int Arch Allergy Immunol 2001, 124:201-204.

45. Dery RE, Ulanova M, Puttagunta L, Stenton GR, James D, Merani S, Mathison R, Davison J, Befus AD: Frontline: Inhibition of allergen-induced pulmonary inflammation by the tripeptide feG: a mimetic of a neuroendocrine pathway. Eur J Immunol 2004, 34:3315-3325.

46. Mathison R, Woodman R, Davison JS: Regulation of leukocyte adhesion to heart by the tripeptides feG and feG(NH2). Can J Physiol Pharmacol 2001, 79:785-792.

47. Mathison R, Lo P, Tan D, Scott B, Davison JS: The tripeptide feG reduces endotoxin-provoked perturbation of intestinal motility and inflammation. Neurogastroenterol Motil 2001, 13:599-603.

48. Mathison R: Submandibular gland peptides and the modulation of anaphylactic and endotoxic reactions. Biomedical Reviews 1998, 9:101-106.

49. Mathison RD, Davison JS, Befus AD: The tripeptide feG reduces perturbation of intestinal motility provoked by anaphylaxis. Proc West Pharmacol Soc 2001, 44:157-158.

50. Tan D, Rougeot C, Davison JS, Mathison R: The carboxamide feG $\left(\mathrm{NH}_{2}\right)$ inhibits endotoxin perturbation of intestinal motility. Eur J Pharmacol 2000, 409:203-205.

51. Mathison R, Davison JS, Befus AD, Abraham WM: The tripeptide feG inhibits asthmatic reactions in sheep. In Immunology 2004. Edited by: Monduzzi E. Montreal Medimond International Proceedings; 2004:515-519.

52. DeClue AE, Schooley E, Nafe LA, Reinero CR: feG-COOH blunts eosinophilic airway inflammation in a feline model of allergic asthma. Inflamm Res 2009, 58:457-462.

53. Eberhardt JM, AE D, CR R: Chronic use of the immunomodulating tripeptide feG-COOH in experimental feline asthma. Vet Immunol Immunopathol 2009, 132:175-180.
54. John SM, Bao F, Chen Y, Mathison RD, Weaver LC: Effects of a novel tripeptide on neurological outcomes after spinal cord injury. Neuroreport 2006, 17:1793-1796.

55. Mathison RD, Befus AD, Davison JS: Reduction in cardiovascular anaphylaxis by submandibular gland peptide-T. Proc West Pharmacol Soc 1997, 40:73-74.

56. Fujishima S, Aikawa N: Neutrophil-mediated tissue injury and its modulation. Intensive Care Med 1995, 21:277-285.

57. Mathison RD, Davison JS: The tripeptide feG regulates the production of intracellular reactive oxygen species by neutrophils. J Inflamm (Lond) 2006, 3:9.

58. von Bültzingslöwen I, Sollecito TP, Fox PC, Daniels T, Jonsson R, Lockhart PB, Wray D, Brennan MT, Carrozzo M, Gandera B, Fujibayashi T, Navazesh M, Rhodus NL, Schiødt M: Salivary dysfunction associated with systemic diseases: systematic review and clinical management recommendations. Oral Surg Oral Med Oral Pathol Oral Radiol Endod 2007, 103:e1-15

59. Williams RC, Barnett AH, Claffey N, Davis M, Gadsby R, Kellett M, Lip GY, Thackray S: The potential impact of periodontal disease on general health: a consensus view. Curr Med Res Opin 2008, 24:1635-1643.

60. Cullinan MP, Ford PJ, Seymour GJ: Periodontal disease and systemic health: current status. Aust Dent J 2009, 54(Suppl 1):S62-69.

61. Lund EM, Armstrong PJ, Kirk CA, Kolar LM, Klausner JS: Health status and population characteristics of dogs and cats examined at private veterinary practices in the United States. J Am Vet Med Assoc 1999, 214:1336-1341

62. Niemiec BA: Periodontal disease. Top Companion Anim Med 2008, 23:72-80.

63. Reiter AM, Brady CA, Harvey CE: Local and systemic complications in a cat after poorly performed dental extractions. J Vet Dent 2004, 21:215-221.

64. DeBowes LJ, Mosier D, Logan E, Harvey CE, Lowry S, Richardson DC: Association of periodontal disease and histologic lesions in multiple organs from 45 dogs. J Vet Dent 1996, 13:57-60.

65. Vane JR: Inhibition of prostaglandin synthesis as a mechanism of action for aspirin-like drugs. Nat New Biol 1971, 231:232-235.

66. Zarbock A, Ley K: Mechanisms and consequences of neutrophil interaction with the endothelium. Am J Pathol 2008, 172:1-7.

67. Brady CA, Otto CM: Systemic inflammatory response syndrome, sepsis, and multiple organ dysfunction. Vet Clin North Am Small Anim Pract 2001, 31:1147-1162, v-vi.

68. Belknap JK: The pharmacologic basis for the treatment of developmental and acute laminitis. Vet Clin North Am Equine Pract 2010, 26:115-124.

69. FIM Rationale and Proposed Guidelines for the Nutraceutical Research \& Education Act - NREA. [http://www.fimdefelice.org/archives/arc.researchact. html]

doi:10.1186/1476-9255-7-49

Cite this article as: Mathison et al:: Salivary gland derived peptides as a new class of anti-inflammatory agents: review of preclinical pharmacology of C-terminal peptides of SMR1 protein. Journal of Inflammation 2010 7:49

\section{Submit your next manuscript to BioMed Central and take full advantage of:}

- Convenient online submission

- Thorough peer review

- No space constraints or color figure charges

- Immediate publication on acceptance

- Inclusion in PubMed, CAS, Scopus and Google Scholar

- Research which is freely available for redistribution

Submit your manuscript at www.biomedcentral.com/submit
C Biomed Central 